\title{
A highly oriented cubic phase formed by lipids under shear
}

Article

Accepted Version

Seddon, A. M., Lotze, G., Plivelic, T. S. and Squires, A. M. (2011) A highly oriented cubic phase formed by lipids under shear. Journal of the American Chemical Society, 133 (35). pp. 13860-13863. ISSN 0002-7863 doi: https://doi.org/10.1021/ja2053336 Available at https://centaur.reading.ac.uk/22872/

It is advisable to refer to the publisher's version if you intend to cite from the work. See Guidance on citing.

Published version at: http://dx.doi.org/10.1021/ja2053336

To link to this article DOI: http://dx.doi.org/10.1021/ja2053336

Publisher: American Chemical Society

All outputs in CentAUR are protected by Intellectual Property Rights law, including copyright law. Copyright and IPR is retained by the creators or other copyright holders. Terms and conditions for use of this material are defined in the End User Agreement.

\section{www.reading.ac.uk/centaur}

\section{CentAUR}

Central Archive at the University of Reading 
Reading's research outputs online 


\title{
A Highly Oriented Cubic Phase Formed by Lipids under Shear
}

\author{
Annela M. Seddon, ${ }^{*,+\S}$ Gudrun Lotze, ${ }^{\neq}$Tomás S. Plivelic, ${ }^{\perp}$ and Adam M. Squires ${ }^{*,+}$ \\ ${ }^{\dagger}$ H.H. Wills Physics Laboratory, Tyndall Avenue, University of Bristol, Bristol BS8 1TL, United Kingdom \\ ${ }^{\S}$ Bristol Centre for Functional Nanomaterials, Nanoscience and Quantum Information Building, Tyndall Avenue, University of Bristol, \\ Bristol BS8 1FD, United Kingdom \\ ${ }^{\ddagger}$ School of Chemistry, Whiteknights Campus, University of Reading, Reading RG6 6AD, United Kingdom \\ ${ }^{\perp}$ MAX IV Laboratoriet, Lund University, 22100 Lund, Sweden
}

Supporting Information

ABSTRACT: We demonstrate the formation of a macroscopically oriented inverse bicontinuous cubic ( $\mathrm{QII}_{\mathrm{II}}$ ) lipid phase from a sponge $\left(\mathrm{L}_{3}\right)$ phase by controlled hydration during shear flow. The $\mathrm{L}_{3}$ phase was the monoolein/ butanediol/water system; the addition of water reduces the butanediol concentration, inducing the formation of a diamond $\left(Q_{I I}{ }^{D}\right)$ cubic phase, which is oriented by the shear flow. The phenomenon was reproduced in both capillary and Couette geometries, indicating that this represents a robust general route for the production of highly aligned bulk $\mathrm{Q}_{\mathrm{II}}$ samples, with applications in nanomaterial templating and protein research.

Tnverse bicontinuous cubic $\left(\mathrm{Q}_{\mathrm{II}}\right)$ phases are nanostructured 1 materials formed by lipid self-assembly. In this paper, we demonstrate a method for the production of a macroscopically oriented sample of a $\mathrm{Q}_{\mathrm{II}}$ phase.

Biological amphiphiles such as lipids are known to be capable of forming 3-D self-assembled nanostructures known as $\mathrm{Q}_{\mathrm{II}}$ phases. ${ }^{1}$ Three such cubic phases have been reported, known as the Diamond $\left(Q_{I I}{ }^{D}\right)$, Gyroid $\left(Q_{I I}^{G}\right)$, and Primitive $\left(Q_{I I}^{P}\right)$, illustrated in Figure 1. In each case, the lipid molecules form an intricately curved fluid bilayer, on either side of which lie two interpenetrating continuous networks of water channels. The structures of $\mathrm{Q}_{\mathrm{II}}$ phases possess a number of remarkable features that have significant potential for nanotechnological applications. They contain water channels of the order of $2-5 \mathrm{~nm}$ in diameter, whose size is extremely uniform throughout the sample, the dimensions of which may be tuned by controlling the temperature (in excess water) or the lipid/water ratio (below excess water). ${ }^{2}$ The structure also provides an extremely efficient way of packing a very large contiguous surface area into a small volume. ${ }^{3}$ Such properties make these, and similar structurally analogous materials, promising candidates in applications where they may be templated for size-selective molecular sieves or catalysts ${ }^{4}$ or for electronic applications. ${ }^{5}$ They have also shown success as a matrix for the crystallization of membrane proteins ${ }^{6}$ and as a host for siRNA. ${ }^{7}$ Moreover, given the biological origin of the amphiphiles, and the similarity of the bilayer environment within the $\mathrm{Q}_{\mathrm{II}}$ phase to a cell membrane, they have much more widespread potential in protein research. ${ }^{8}$ However, until now research has almost exclusively employed bulk samples containing billions of randomly oriented domains. ${ }^{9}$ In general, single crystal or oriented monodomain materials can have vastly different properties as compared with their polydomain or powder-like analogues. For example, internal domain boundaries can potentially affect transport, mechanical and optical properties. ${ }^{10}$ Specifically for bicontinuous cubic phases, the internal domain boundaries are known to affect phase transition kinetics. ${ }^{11}$ Macroscopically oriented materials also yield information that cannot be obtained from powder-like samples, especially when studied using diffraction techniques such as small-angle X-ray scattering (SAXS), which is a major technique for structural studies of cubic phases. ${ }^{12,13}$ For example, the mechanism of interconversion of lyotropic phases cannot be determined unambiguously using powder-like samples. ${ }^{13}$ There are many other instances of research where X-ray scattering analysis yields more information as a result of sample orientation, for example, on a surface $^{14}$ or of fibers oriented by flow. ${ }^{15}$

It would therefore be advantageous if there were a method to produce macroscopically oriented cubic phases of biological amphiphiles. The work we present here demonstrates such a method, based on the transformation of a disordered precursor "sponge" phase into a cubic phase under controlled hydration during shear flow.

The sponge or $\mathrm{L}_{3}$ phase can be considered as a disordered cubic phase which still displays a bicontinuous network of water channels separated by a lipid bilayer. ${ }^{17}$ It possesses short-range order; however, it is disordered over longer length scales. Amphiphiles which spontaneously form cubic phases are often seen to form $\mathrm{L}_{3}$ phases in the presence of additives which cause a relaxation of the curvature of the cubic phase, leading to this disordered structure. ${ }^{18,19}$ Structurally analogous systems formed by surfactant/brine mixtures have been well characterized in the past. ${ }^{16,20}$ The $\mathrm{L}_{3}$ phase formed by lipids has been documented in detail in the case of the lipid 1-monoolein (MO) in the presence of additives commonly found in membrane protein crystallization; ${ }^{18}$ indeed, it is postulated that in-cubo crysallization may occur via an $\mathrm{L}_{3}$ intermediate. In contrast to the $Q_{\text {II }}$ phases which are extremely stiff with typical shear modulus of the order of hundreds of kilopascals; ${ }^{21}$ the $\mathrm{L}_{3}$ phase has a much lower viscosity, and flows as a liquid. ${ }^{22}$

Received: June 9, 2011 

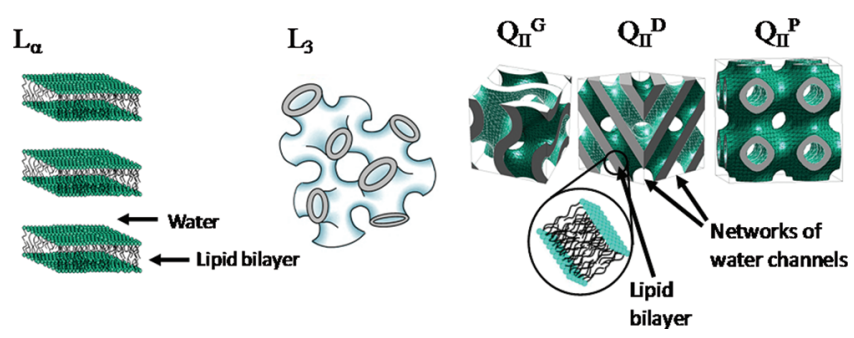

Figure 1. The bicontinuous phases formed by monoolein. From left to right, the $\mathrm{L}_{3}$, or sponge, phase (image adapted from ref 16 ); the $\mathrm{Q}_{\mathrm{II}}^{\mathrm{G}}$ (gyroid), the $\mathrm{Q}_{\mathrm{II}}^{\mathrm{D}}$ (diamond), and the $\mathrm{Q}_{\mathrm{II}}^{\mathrm{P}}$ (primitive) inverse bicontinuous cubic phases.

In this work, the $\mathrm{L}_{3}$ phase formed by $\mathrm{MO}$, in the presence of 1,4-butanediol and water, is transformed to a $\mathrm{Q}_{\mathrm{II}}^{\mathrm{D}}$ phase by reducing the concentration of 1,4-butanediol. This process involves controlled dilution of the sample. Furthermore, by performing this dilution under shear flow, both in a flow cell and a Couette cell, a macroscopically oriented cubic phase was formed. The phase diagram of the $\mathrm{MO} /$ butanediol/water system $^{18}$ shows that for a fixed w/w ratio of MO to "solvent" (i.e., the mixture of butanediol and water), three distinct phases are formed depending on the butanediol/water ratio. Below $25 \%$ (v/v) butanediol, the $P n 3 m$ phase is observed. From $25 \%$ to $\sim 45 \%$ butanediol, the sample exists in the $\mathrm{L}_{3}$ phase. At butanediol concentrations $>45 \%$ of the total volume of solvent, a fluid lamellar phase is observed. This can be rationalized by consideration of the effect of an amphiphilic additive such as butanediol on the interfacial curvature of the lipid membrane. Interactions of the butanediol with both the polar/apolar interface and the apolar region of the bilayer causes swelling of the aqueous channels and relaxation of the bilayers such that the cubic phase becomes disordered and phases with flatter interfaces such as the $\mathrm{L}_{3}$ or the fluid lamellar phase emerge. Here, we have started with a butanediol concentration of $40 \%$; by adding water, we have effectively lowered the concentration of butanediol causing the sample to move into the $\mathrm{Q}_{\mathrm{II}}^{\mathrm{D}}$ phase-removal of butanediol effectively increases the interfacial curvature of the membrane. By performing this dilution under shear, as the cubic phase forms, it macroscopically orientates leading to the highly ordered material shown in our work.

A 60:40 (v/v) solution of water/1,4-butanediol was prepared and mixed with MO (Rylo, received as a gift from Danisco) in a 60:40 (w/w) solvent/MO ratio. The sample underwent 2 freeze thaw cycles to form an optically isotropic viscous liquid. Data was collected at I711 at Max-lab in a custom built syringe pump driven flow cell using $1.5 \mathrm{~mm}$ internal diameter fluorinated ethylene propylene (FEP) tubing connected to a $1.5 \mathrm{~mm}$ diameter thin walled borosilicate glass $\mathrm{X}$-ray capillary. The beam size at the sample was $0.35 \times 0.35 \mathrm{~mm}$ (full width at halfmaximum, fwhm). Data were also collected at the ID02 high brilliance beamline at the ESRF using a Haake RS300 rheometer fitted with an X-ray transparent polyimide Couette cell (inner diameter $20 \mathrm{~mm}$, outer diameter $22 \mathrm{~mm}$, height $40 \mathrm{~mm}, 1 \mathrm{~mm}$ gap). The $\mathrm{L}_{3}$ phase was loaded into either the flow cell or Couette cell and a static SAXS pattern was measured, confirming the presence of the $\mathrm{L}_{3}$ phase. For the flow cell, water was loaded into the FEP tubing and separated from the $\mathrm{L}_{3}$ phase by an air gap of approximately $5 \mu \mathrm{L}$. The sample was flowed back and forth at a volume flow rate of $10 \mu \mathrm{L} \mathrm{s}{ }^{1-}$ and a displaced volume of $50 \mu \mathrm{L}$

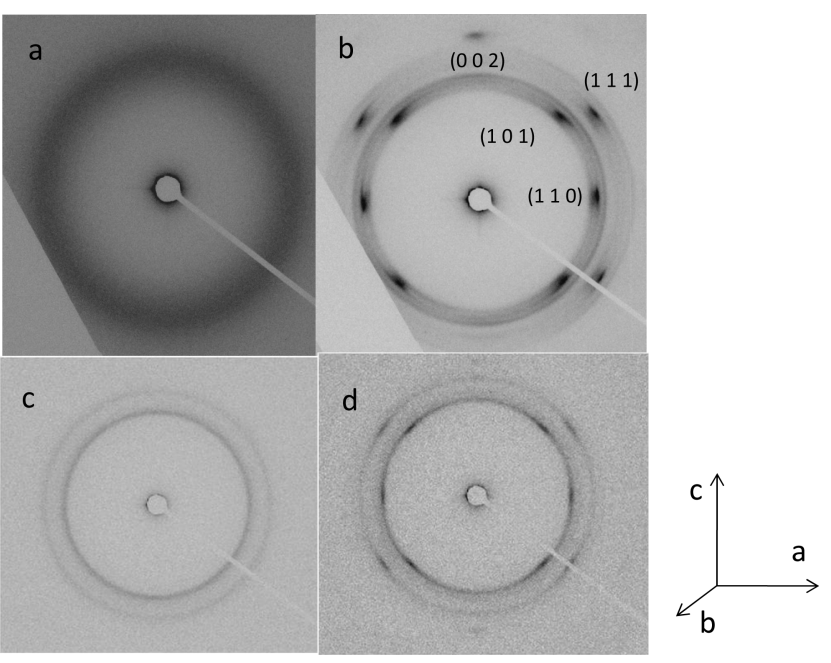

Figure 2. Data collected from the flow cell: (a) The $\mathrm{L}_{3}$ phase formed prior to flow; (b) the oriented $\mathrm{Q}_{\mathrm{II}}^{\mathrm{D}}$ phase formed after oscillatory flow has been applied. The cubic phase shows cylindrical symmetry about the (001) (c) axis; (c) data collection in first $30 \mathrm{~s}$ reveals that cubic phase is formed (d) which subsequently aligns. In the axis system shown, the $\mathrm{X}$-ray beam passes in the (b) direction, while (c) represents the capillary axis and thus the direction of flow.

(approximately $36 \mathrm{~mm}$ linear displacement). In the case of the Couette cell, a known volume of water was added manually between the inner and outer walls of the Couette. Large amplitude oscillatory shear was applied at a frequency of $1 \mathrm{~Hz}$ at a strain amplitude of $\gamma=1000$. Images were recorded over a range of time scales with an exposure time of either 10 or $60 \mathrm{~s}$ (Max-lab) or $0.1-1 \mathrm{~s}$ (ESRF). The images were analyzed using a custom written macro in ImageJ. Integrated data are given in the Supporting Information.

Figure 2 shows the data collected in the flow cell. Figure 2a illustrates that the $\mathrm{MO} /$ butanediol/water sample is in an $\mathrm{L}_{3}$ phase prior to dilution, or to the application of shear flow as observed previously. ${ }^{18}$ As water was added to the sample under oscillatory shear or flow, butanediol was effectively diluted leading to an increased interfacial curvature and the formation of a highly oriented $\mathrm{Q}_{\mathrm{II}}{ }^{\mathrm{D}}$ phase shown in Figure $2 \mathrm{~b}$. The scattering pattern is consistent with an oriented cubic phase arranged with the [010] axis parallel to the flow direction, which is vertical as shown in the image. The diffraction pattern is rotationally averaged about this direction due to the symmetry of the flow apparatus. Data collection in first $30 \mathrm{~s}$ reveals that a cubic phase is formed which subsequently aligns. This is shown in Figure $2 c, d$. We estimate from the experiments carried out in the Couette cell that we moved from a butanediol ratio of $40 \%(\mathrm{v} / \mathrm{v})$ to $15 \%(\mathrm{v} / \mathrm{v})$ which would be sufficient to drive a phase transition from $\mathrm{L}_{3}$ to $\mathrm{Q}_{\mathrm{II}}^{\mathrm{D}}$ in agreement with previous observations. ${ }^{18}$

While the observed lattice parameters of the $\mathrm{L}_{3}$ and $\mathrm{Q}_{\mathrm{II}}{ }^{\mathrm{D}}$ samples are smaller than those observed previously, ${ }^{18}$ the lattice parameter of the $\mathrm{Q}_{\mathrm{II}}^{\mathrm{D}}$ is still swollen by $37.5 \AA$ (from $a=100 \AA^{23,24}$ previously seen for MO in water to $137.5 \AA$, decreasing to $125.5 \AA$ over the course of the alignment) above what would be seen for a $\mathrm{Q}_{\mathrm{II}}^{\mathrm{D}}$ formed by $\mathrm{MO}$ and water and confirms that the addition of 1,4-butanediol causes the sample to swell. The data taken in the Couette cell follows the same pattern (data not shown).

Shear was halted and images were recorded to examine the stability of the oriented cubic phase. During a $10 \mathrm{~min}$ period, no 

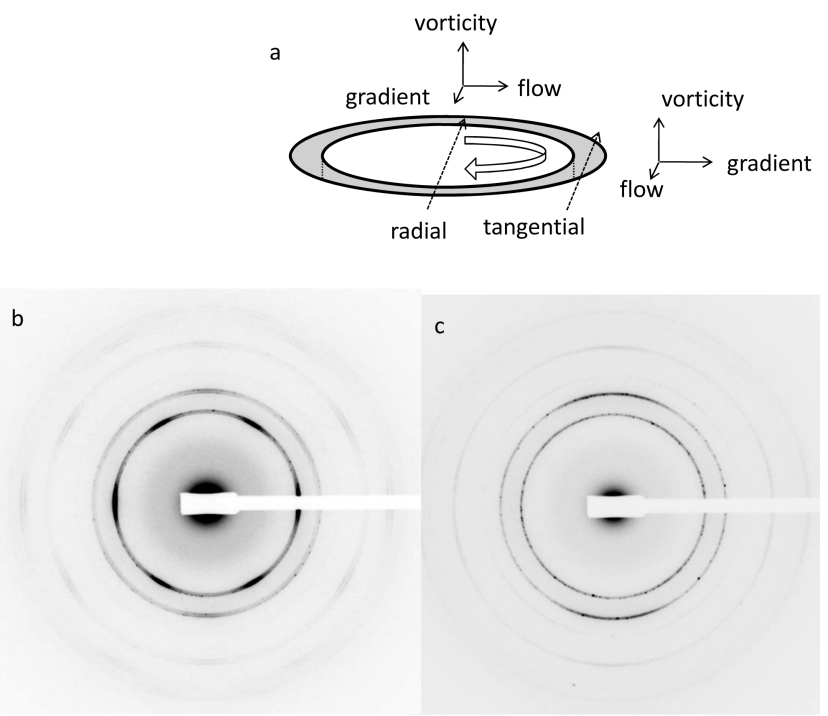

Figure 3. Data collected from the Couette cell: (a) schematic showing the direction of flow of the sample relative to the X-ray beam path; (b) SAXS pattern of an aligned $\mathrm{Q}_{\mathrm{II}}^{\mathrm{D}}$ phase taken radial to the beam path; (c) the aligned $\mathrm{Q}_{\mathrm{II}}{ }^{\mathrm{D}}$ phase viewed tangential to the beam path.

change was observed in the sample, indicating that, at least over this time scale, the sample was stable in an aligned configuration.

Data were collected in a Couette cell to examine the alignment of the sample both radial and tangential to the X-ray beam. These patterns are shown in Figure 3. Two scattering patterns were obtained, with the beam passing radially (through the center of the Couette cell cylinders) and tangentially (in between the cylinders, on one side). In the radial geometry, the beam passes in the shear gradient direction, and the scattering pattern shows the vorticity-flow plane (illustrated schematically in Figure 3a). The pattern is the superposition of scattering from the front and back of the cylinder, leading to the closely spaced double reflections that can be seen in Figure $3 \mathrm{~b}$. The pattern again shows a high degree of orientation. In this case, there is a pronounced 6-fold rotational symmetry about the beam direction, possibly suggesting that the beam is passing along a body diagonal ( $\langle 111\rangle$ axis) of the cubic phase. The tangential scattering pattern shown in Figure $3 \mathrm{c}$ shows a much lower degree of orientation, suggesting some level of rotational disorder about the flow direction.

Overall, the flow cell appears to provide more oriented samples, although, in general, Couette cells provide better defined shear flow regimes. Interestingly, the two methods provide cubic phases with different orientations.

Previous work on sheared type I ("normal") cubic phases ${ }^{25}$ showed that when a cubic phase formed by a nonionic surfactant subjected to shear in a Couette cell, "melting" of the cubic phase into what was postulated to be the $\mathrm{L}_{3}$ phase occurred. Upon cessation of shear, the cubic phase reformed; however, now it displayed a preferred orientation. Single crystals of a $\mathrm{Q}_{\mathrm{II}}^{\mathrm{G}}$ phase have also been observed previously in surfactant and block copolymer systems; however, these have been grown epitaxially from corresponding lamellar or hexagonal phases. ${ }^{26-28}$

We suggest that the ability to form an aligned cubic phase of this nature opens up the possibility of improved nanostructured templating applications, enhanced in cubo crystallization of proteins and increased structural information on globular and membrane proteins incorporated within the cubic matrix. ${ }^{6,29}$
Starting from an $\mathrm{L}_{3}$ phase has practical advantages, namely, that its low viscosity compared to the $\mathrm{Q}_{\mathrm{II}}{ }^{\mathrm{D}}$ phase allows facile loading of the sample into a flow cell. In conclusion, we have shown that by starting from a disordered precursor phase in the form of the $\mathrm{L}_{3}$ phase formed by $\mathrm{MO}$ and butanediol, it is possible to produce an aligned macroscopically oriented cubic phase of lipid.

\section{ASSOCIATED CONTENT}

S Supporting Information. Integrated SAXS data for Figures $2 \mathrm{a}-\mathrm{d}$ and $3 \mathrm{~b}, \mathrm{c}$. This material is available free of charge via the Internet at http://pubs.acs.org.

\section{AUTHOR INFORMATION}

\section{Corresponding Authors}

annela.seddon@bristol.ac.uk; a.m.squires@reading.ac.uk

\section{ACKNOWLEDGMENT}

G.L. is supported by funding from the University of Reading and the Diamond Light Source. We thank the ESRF and Max-lab for the provision of beamtime.

\section{REFERENCES}

(1) Luzzati, V.; Delacroix, H.; Gulik, A.; GulikKrzywicki, T.; Mariani, P.; Vargas, R. Lipid Polymorphism and Membrane Properties; Academic Press: San Diego, CA, 1997; Vol. 44, pp3-24.

(2) Squires, A. M.; Seddon, J. M.; Templer, R. H.; Templer, R. H.; Leatherbarrow, R. Biophysical Chemistry: Membranes and Proteins; The Royal Society of Chemistry: Cambridge, U.K., 2002; p 177-190.

(3) Shearman, G. C.; Ces, O.; Templer, R. H.; Seddon, J. M. J. Phys.: Condens. Matter 2006, 18, S1105-S1108.

(4) Holyst, R. Nat. Mater. 2005, 4, 584-584.

(5) Wang, D. H.; Luo, H. M.; Kou, R.; Gil, M. P.; Xiao, S. G.; Golub, V. O.; Yang, Z. Z.; Brinker, C. J.; Lu, Y. F. Angew. Chem., Int. Ed. 2004, $43,6169-6173$.

(6) Caffrey, M. Ann. Rev. Biophys. 2009, 38, 29-51.

(7) Leal, C. 1.; Bouxsein, N. F.; Ewert, K. K.; Safinya, C. R. J. Am. Chem. Soc. 2011, 132, 16841.

(8) Bilewicz, R.; Rowinski, P.; Rogalska, E. Bioelectrochemistry 2005, 66, 3-8.

(9) Rittman, M.; Frischherz, M.; Burgmann, F.; Hartley, P. G.; Squires, A. Soft Matter 2010, 6, 4058-4061.

(10) Biggins, J. S.; Warner, M.; Bhattacharya, K. Phys. Rev. Lett. 2009, 103, 037802 .

(11) Conn, C. E.; Ces, O.; Mulet, X.; Finet, S.; Winter, R.; Seddon, J. M.; Templer, R. H. Phys. Rev. Lett. 2006, 96, 108012.

(12) Squires, A. M.; Templer, R. H.; Seddon, J. M.; Woenckhaus, J.; Winter, R.; Finet, S.; Theyencheri, N. Langmuir 2002, 18, 7384-7392.

(13) Squires, A. M.; Templer, R. H.; Seddon, J. M.; Woenkhaus, J.; Winter, R.; Narayanan, T.; Finet, S. Phys. Rev. E 2005, 72, 011502.

(14) Caracciolo, G.; Amenitsch, H.; Sadun, C.; Caminiti, R. Chem. Phys. Lett. 2005, 405, 252-257.

(15) Squires, A. M.; Devlin, G. L.; Gras, S. L.; Tickler, A. K.; MacPhee, C. E.; Dobson, C. M. J. Am. Chem. Soc. 2006, 128, $11738-11739$.

(16) Porcar, L.; Hamilton, W. A.; Butler, P. D.; Warr, G. G. Phys. Rev. Lett. 2004, 93, 198301.

(17) Porte, G. Curr. Opin. Colloid Interface Sci. 1996, 1, 345-349.

(18) Cherezov, V.; Clogston, J.; Papiz, M. Z.; Caffrey, M. J. Mol. Biol. 2006, 357, 1605-1618.

(19) Wadsten-Hindrichsen, P.; Bender, J.; Unga, J.; Engstrom, S. J. Colloid Interface Sci. 2007, 315, 701-713. 
(20) Hamilton, W. A.; Porcar, L.; Butler, P. D.; Warr, G. G. J. Chem. Phys. 2002, 116, 8533-8546.

(21) Mezzenga, R; Meyer, C.; Servais, C.; Romoscanu, A. I.; Sagalowicz, L.; Hayward, R. C. Langmuir 2005, 21, 3322-3333.

(22) Munoz, J.; Alfaro, M. C. Grasas Aceites 2000, 51, 6-25.

(23) Briggs, J.; Chung, H.; Caffrey, M. J. Phys. II 1996, 6, 723.

(24) Qiu, H.; Caffrey, M. Biomaterials 2000, 21, 223-234.

(25) Olsson, U.; Mortensen, K. J. Phys. II 1995, 5, 789-801.

(26) Rancon, Y.; Charvolin, J. J. Phys. (Paris) 1987, 48, 1067-1073.

(27) Rancon, Y.; Charvolin, J. J. Phys. Chem. 1988, 92, 2646-2651.

(28) Schulz, M. F.; Bates, F. S.; Almdal, K.; Mortensen, K. Phys. Rev. Lett. 1994, 73, 86-89.

(29) Zabara, A.; Amar-Yuli, I.; Mezzenga, R. Langmuir 2011, 27, 6418-6425. 